\title{
SPIRITUALITY BUILDING BAGI LANSIA: PENGALAMAN PENDAMPINGAN PADA LANSIA DI DESA KARE KECAMATAN KARE KABUPATEN MADIUN
}

\author{
Lilik Rahmawati, Khofifatul Qolbi, Khusnul Khotimah
}

UIN Sunan Ampel Surabaya

\begin{abstract}
Abstrak
Kebahagiaan manusia yang hakiki dapat diperoleh dari konsistensi mentaati suatu aturan tertentu. Agama Islam sangat menganjurkan pemeluknya untuk memahami tata cara ibadah seperti sholat dan wudhu. Pelaksanaan pengabdian masyarakat ini memfokus pada pendampingan spiritualitas pada lansia Desa Kare Madiun dalam bentuk pelatihan sholat dan wudhu. Pendampingan ini mempunyai beberapa tujuan. Pertama, untuk menghasilkan suatu perubahan, perbaikan, kesehatan, dan kebersihan jiwa dan mental masyarakat Desa Kare khususnya Lansia Desa Kare. Kedua, adanya perubahan dan perbaikan dalam aspek kesopanan tingkah laku yang dapat memberikan manfaat, baik pada diri sendiri, lingkungan keluarga, lingkungan kerja, maupun lingkungan sosial dan alam sekitar. Ketiga, mendukung keberhasilan kecerdasan rasa (emosi) pada lansia sehingga berkembang praktik toleransi, kasih sayang, kesetiakawanan, dan tolong menolong. Keempat, mendukung ketercapaian kecerdasan spiritual pada lansia sehingga mendorong kualitan ketakwaan kepada Allah SWT. Pelatihan pendalaman agama ini menggunakan metode ekspository berupa program kajian rutin dimulai dari tanggal 26 Juli sampai 10 Agustus 2016 disertai program tambahan berupa pengkaderan.
\end{abstract}

Kata Kunci: Lansia, Pelatihan, Wudhu, Sholat.

\begin{abstract}
Essential human happiness can be obtained from consistency in obeying certain rules. Islam strongly encourages its adherents to understand the procedures of worship such as prayer and ablution. The implementation of community service focuses on spirituality assistance in the elderly Kare Madiun Village in the form of prayer and ablution training. This assistance has several objectives. First, to produce a change, improvement, health, and cleanliness of the soul and mentality of the Kare Village community, especially the Kare Village Elderly. Second, there are changes and improvements in aspects of courtesy that can provide benefits, both to oneself, family environment, work environment, and the social and natural environment. Third, it supports the success of sense intelligence (emotion) in the elderly so that it develops the practice of tolerance, affection, solidarity, and help. Fourth, to support the achievement of spiritual intelligence in the elderly so as to encourage the quality of piety to Allah SWT. This religious deepening training uses the expository method in the form of a routine study program starting from July 26 to August 10, 2016 accompanied by additional programs in the form of cadre.
\end{abstract}

Keywords: Elderly, Training, Ablution, Prayer.

\section{PENDAHULUAN}

Manusia dalam hidupnya selalu merindukan kebahagiaan. Kebahagiaan yang hakiki ternyata bukanlah berasal dari pola hidup bebas seperti burung, melainkan justru diperoleh melalui pola hidup yang konsisten mentaati suatu aturan tertentu yaitu agama. Aktivitas keagamaan dalam Islam ada yang bersifat wajib, harus dilakukan oleh setiap pemeluknya, namun ada juga yang bersifat anjuran (sunat). Meskipun diwajibkan oleh agama tetapi tidak jarang pemeluknya tidak melakukannya.

Islam sangat menganjurkan pemeluknya untuk memahami tata cara dan kekhususan dari masing masing bentuk ibadah. Salah satunya adalah bentuk kedisiplinan dalam waktu beribadah shalat, hal tersebut sebagaimana yang disebutkan dalam surat An-Nisa' ayat 103 yang artinya: "Sesungguhnya shalat itu adalah kewajiban yang ditentukan waktunya atas orang-orang yang beriman".

Ayat di atas menunjukkan bahwa muslim dituntut untuk disiplin waktu dalan menjalankan ibadah shalat. Kedisiplinan shalat yang baik adalah melaksanakan tepat pada waktunya dan tidak meninggalkanya. Disamping itu, Islam juga menganjurkan agar setiap pemeluknya mengetahui 
dengan pasti syarat dan rukun dari setiap bentuk ibadah.

Pelaksanaan tata cara, syarat dan rukun suatu ibadah dengan benar merupakan kriteria diterimaanya suatu ibadah di sisi Allah SWT. Dalam kaitan pelaksanaan ibadah sehari-hari, masyarakat dengan karakter agraris melakukan ibadah sholat mengikuti ritme pekerjaan keseharian. Masyarakat Desa Kare Kecamatan Kare Madiun adalah mayarakat agraris. Mata pencaharian mereka adalah petani cengkeh, coklat, dan aneka buah-buahan.

Pelaksanaan sholat ashar yang diselenggarakan di surau atau musholla secara berjamaah dilakukan selepas warga petani pulang dari sawah. Tidak ada kegiatan sholat berjamaah waktu dhuhur. Pelaksanaan ibadah sholat di musholla didominasi oleh kalangan orang tua atau lansia. Seringkali ketika musim panen tiba, warga meninggalkan kewajiban sholat. Mencermati kebiasaan pelaksanaan ibadah sholat masyarakat Desa Kare khususnya lansia, maka cukup banyak dijumpai lansia Desa Kare yang belum menjalankan secara benar syarat dan rukun wajib dari ibadah sholat.

Problem utama pada orang-orang tua adalah rasa kesepian dan kesendirian. Sebelumnya mereka sudah biasa melewatkan hari-harinya dengan kesibukan dan pekerjaan yang sekaligus juga merupakan pegangan hidup maka mereka kehilangan kesibukan, sekaligus merasa mulai tidak diperlukan lagi. Bertepatan dengan itu, anak-anak mulai menikah dan meninggalkan rumah, badan mulai lemah dan tidak memungkinkan untuk bepergian jauh. Sebagai akibatnya, semangat mulai menurun, mudah dihinggapi penyakit dan akan mengalami kemunduran-kemunduran mental, yang disebabkan juga oleh mundurnya fungsi otak, seperti lebih sering lupa dan daya konsentrasi berkurang.

Kondisi tersebut juga mempengaruhi kualitas dari ibadah dari para lansia, dengan kondisi fisik yang makin melemah serta tidak adanya anak generasi muda yang memantau dan membimbing aktivitas ibadah mereka membuat kualitas ibadah tersebut menurun. Dengan pertimbangan di atas maka pendampingan yang memfokus pada penguatan spiritual bagi lansia Desa Kare Kecamatan Kare Kabupaten Madiun. Pendampingan ini dilakukan dengan harapan tercipta masyarakat Desa Kare yang agamis khususnya lansia dengan kehidupan yang lebih tentram dan bahagia lahir batin di usia senja mereka.

\section{LANDASAN TEORI}

1. Pengertian Lansia dan Tugas Perkembangan Lansia

Menurut Santrock lansia disebut sebagai masa dewasa akhir, yang dimulai pada usia 60-an dan diperluas sampai sekitar 120 tahun, memiliki rentang kehidupan yang paling panjang dalam perkembangan manusia lima puluh tahun sampai enam puluh tahun.

Menurut para ilmuan lain, Papalia mempelajari tentang lansia dan membaginya kedalam tiga kelompok yaitu: (1) usia tua muda (young old) berusia 65-74 tahun, biasanya masih aktif dan fit; (2) usia tua (old old) berkisar antara usia 75-84 tahun dan; (3) usia lanjut (oldest old) berusia 85 tahun ke atas telah mengalami kesulitan dalam melakukan kegiatan sehari-hari.

Berdasarkan uraian diatas, penelitian ini menggunakan definisi menurut program dunia kesehatan lansia adalah individu yang berusia 55 tahun keatas. Menurut program dunia kesehatan lanjut usia adalah individu yang berusia 55 tahun keatas. Definisi ini berpatokan pada umur harapan hidup tahun 1955 yang berkisar 61-63 tahun dan umur masa pensiun 55 tahun serta UU no. 4 tahun 1965.

2. Tugas Perkembangan Lansia.

Menurut Havighurst sebagaian tugas perkembangan lanjut usia lebih banyak berkaitan dengan kehidupan pribadi seseorang daripada kehidupan orang lain. Adapun tugas perkembangan tersebut antara lain:

a. Menyesuaikan diri dengan menurunnya kekuatan fisik dan kesehatan. Hal ini sering diartikan sebagai perbaikan dan perubahan peran yang pernah dilakukan didalam maupun diluar rumah. Mereka diharapkan untuk mencari kegiatan sebagai pengganti tugas-tugas terdahulu yang menghabiskan sebagaian besar waktu kala mereka masih muda.

b. Menyesuaikan diri dengan masa pensiun dan berkurangnya income (penghasilan) keluarga. Pada usia ini, lansia sudah memasuki masa pensiun dan tidak bekerja lagi, sehingga pemasukan yang ada hanya berasal dari dana pensiun maupun dari pemberian anak-anak mereka.

c. Menyesuaikan diri dengan kematian pasangan hidup. 
Sebagaian besar orang lansia perlu mempersiapkan dan menyesuaikan diri dengan peristiwa kematian suami atau istri. Kejadian seperti ini lebih menjadi masalah dengan peristiwa kematian suami atau istri. Dimana kematian suami berarti berkurangnya pendapatan dan timbul bahaya karena hidup sendiri dan melakukan perubahan dalam aturan hidup.

d. Membentuk hubungan dengan orang-orang yang sesuai.

Pada lansia, mereka membangun ikatan dengan anggota dari kelompok usia mereka, untuk menghindari kesepian akibat ditinggalkan anak yang tumbuh besar dan masa pensiun.

e. Membentuk pengaturan kehidupan fisik yang memuaskan.

Menyadari bahwa menurunnya kesehatan dan fungsi-fungsi fisik, pada masa lansia mereka berusaha untuk mempertahankan dan mengatur kegiatan sehari-hari yang berhubungan dengan kesehatan, yakni berolahraga maupun mengatur pola makan.

f. Menyesuaikan diri dengan peran sosial secara luwes.

Pada lansia, individu mengalami perubahan peran. Dimana, para lansia mempunyai pengalaman lebih daripada orang yang lebih muda, sehingga peran lansia biasanya diminta untuk memberi pendapat, masukan ataupun kritikan, dan partisipasi lansia terhadap kehidupan sosial menurun biasanya disebabkan oleh masalah fisik.

3. Pendampingan Keagamaan (Wudhu dan Sholat)

Sholat adalah ibadah wajib bagi setiap muslim, dibarengi dengan wudhu sebagai syarat sah dari ibadah sholat, maka dirasa sangat perlu untuk memahami kedua ibadah tersebut untuk menuju kepada manusia sempurna yang bahagia dengan ridho illahi robbi.

Pendampingan spiritualitas sholat ini dimaksudkan untuk untuk menghasilkan suatu perubahan, perbaikan, kesehatan, dan kebersihan jiwa dan mental masyarakat Desa Kare khususnya Lansia Desa Kare. Jiwa menjadi tenang, damai (muthmainnah), bersikap lapang dada (radhiyah), dan mendapatkan pencerahan taufik dan hidayah Tuhan (mardhiyah). Manfaat kedua yang diharapkan dari dengan pendalaman sholat ini untuk menghasilkan suatu perubahan, perbaikan dan kesopanan tingkah laku yang dapat memberikan manfaat, baik pada diri sendiri, lingkungan keluarga, lingkungan kerja, maupun lingkungan sosial dan alam sekitar. Ketiga, untuk menghasilkan kecerdasan rasa (emosi) pada individi sehingga muncul dan berkembang rasa toleransi, kesetiakawanan, tolong menolong, dan rasa kasih sayang. Keempat, untuk menghasilkan kecerdasan spiritual pada individu sehingga muncul dan berkembang rasa keinginan untuk berbuat taat kepada Tuhannya, ketulusan mematuhi segala perintah-Nya, serta ketabahan menerima ujianNya. Kelima, untuk menghasilkan potensi Illahi, sehingga dengan potensi itu individu dapat melakukan tugasnya sebagai khalifah dengan baik dan benar, dapat dengan baik menanggulangi berbagai persoalan.

Keempat manfaat diatas akan mendukung terbentuknya masyarakat yang agamis dan bermanfaat bagi sekitar, dapat menjadikan Desa Kare sebagai desa yang dipenuhi masyarakat sehat jiwa dan bahagia dengan keimanan dan ketaqwaan kepada Allah SWT.

\section{a. Pengertian Wudhu}

Menurut bahasa, Wudhu artinya Bersih dan Indah. sedangkan menurut istilah (syariah islam) artinya menggunakan air pada anggota badan tertentu dengan cara tertentu yang dimulai dengan niat guna menghilangkan hadast kecil. Wudhu merupakan salah satu syarat sahnya sholat (orang yang akan sholat, diwajibkan berwudhu lebih dulu, tanpa wudhu shalatnya tidak sah.

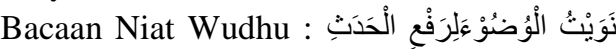

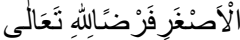

"Aku niatberwudhu untuk menghilangkan hadats kecil, fardhu karena Allah."

Apabila seorang muslim mau berwudhu maka hendaknya ia berniat di dalam hatinya kemudian membaca "Bismillahirrahmanirrahim" sebab Rasulullah SAW bersabda "Tidak sah wudhu orang yg tidak menyebut nama Allah". Dan apabila ia lupa maka tidaklah mengapa. Jika hanya mengucapkan "Bismillah" saja maka dianggap cukup.

Rukun kedua wudhu adalah mencuci muka. Batas muka adalah dari batas tumbuhnya 
rambut kepala bagian atas sampai dagu dan mulai dari batas telinga kanan hingga telinga kiri, dan jika rambut yg ada pada muka tipis maka wajib dicuci hingga pada kulit dasarnya. Tetapi jika tebal maka wajib mencuci bagian atasnya saja namun disunnahkan mencelahcelahi rambut yg tebal tersebut. Karena Rasulullah selalu mencelah-celahi jenggotnya di saat berwudhu.

Rukun ketiga mencuci kedua tangan sampai siku krn Allah berfirman "dan kedua tanganmu hingga siku." Kemudian mengusap kepala beserta kedua telinga satu kali dimulai dari bagian depan kepala lalu diusapkan ke belakang kepala lalu mengembalikannya ke depan kepala. Setelah itu langsung mengusap kedua telinga dgn air yg tersisa pada tangannya.

Rukun wudhu selanjutnya adalah mencuci kedua kaki sampai kedua mata kaki karena Allah SWT berfirman "dan basuhlah kedua kakimu hingga dua mata kaki.". Yang dimaksud mata kaki adalah benjolan yg ada di sebelah bawah betis. Kedua mata kaki tersebut wajib dicuci berbarengan dgn kaki. Orang yg tangan atau kakinya terpotong maka ia mencuci bagian yg tersisa yg wajib dicuci. Dan apabila tangan atau kakinya itu terpotong semua maka cukup mencuci bagian ujungnya saja.

Ibadah wudhu mewajibkan muslim untuk mencuci anggota-anggota wudhunya secara berurutan tidak menunda pencucian salah satunya hingga yg sebelumnya kering. Hal ini berdasar hadits yg diriwayatkan Ibn Umar Zaid bin Sabit dan Abu Hurairah bahwa Nabi senantiasa berwudu secara berurutan kemudian beliau bersabda "Inilah cara berwududi mana Allah tidak akan menerima shalat seseorang kecuali dgn wudu seperti ini.".

b. Pengertian Sholat

Hasan menjelaskan bahwa shalat menurut bahasa (etimologi) adalah doa, sedangkan shalat menurut istilah (terminologi) adalah semua ucapan dan perbuatan yang bersifat khusus yang dimulai dengan takbir dan disudahi dengan salam, dan memenuhi beberapa syarat yang ditentukan, Allah mewajibkan kepada setiap muslim laki-laki dan wanita shalat lima kali dalam sehari semalam.

Waktu shalat wajib ada lima, yaitu:

1) Waktu dhuhur
Mulai sejak tergelincirnya matahari hingga bayangan setiap benda sama seperti bendanya selain bayangan istiwa' (bayang benda pada saat matahari berda pada pertengahan langit), shalat dhuhur leibih baik dilakukan segera kecuali dalam kondisi yang sangat panas, sunnahnya diakhirkan sehingga panas menurun menjadi dingin, dikerjakan dengan empat rakaat.

2) Waktu asar

Mulai sejak habisnya waktu dhuhur hingga matahari berwarna kekuning-kuningan, dan waktu darurat (yaitu wajib dilakukan dengan segera) sampai terbenamnya matahari. Shalat ini disunnahkan agar segera dilaksanakan, dan jumlahnya empat rakaat.

3) Waktu maghrib

Mulai sejak terbenamnya matahari sampai hilangnya mega-mega merah, dan shalat ini dianjurkan untuk disegerakan, dan jumlahnya tiga rakaat.

4) Waktu isya'

Mulai dari hilangnya mega merah sampai pertengahan malam, adapun waktu darurat, hingga terbitnya fajar kedua, jika memungkinkan dianjurkan untuk mengakhirkannya sampai sepertiga malam, jumlahnya empat rakaat.

5) Waktu subuh

Mulai sejak terbit fajar yang kedua hingga terbitnya matahari, shalat ini lebih baik disegerakan, dan jumlahnya dua rakaat.

Syarat-Syarat Shalat yaitu Suci dari hadats kecil dan hadats besar, Badan, pakaian, dan tempat shalat suci dari najis, kemudian masuknya waktu shalat, selanjutnya memakai pakian bersih yang menutupi aurat, lalu menghadap kiblat dan Niat, berniat dalam hati untuk melaksanakan shalat sebelum takbiratul ihram, dan tidak melafadzakannya dengan lisan.

\section{PELAKSANAN PENDAMPINGAN SPIRITULITAS LANSIA}

\section{Metode Pendampingan}

Metode yang digunakan dalam pelatihan pendalaman spiritual masyarakat pada lansia Desa Kare adalah metode pembelajaran ekspositori atau metode pembelajaran yang menekankan kepada proses 
penyampaian materi secara verbal dari seorang pendamping kepada sekelompok dampingan dengan maksud agar dampingan dapat menguasai materi secara optimal.

Ada beberapa langkah dalam penerapan metode ekspositori dalam pendampingan spiritualitas lansia, yaitu:

a. Persiapan (Preparation)

a. Tahap persiapan berkaitan dengan mempersiapkan para lansia untuk menerima pelajaran. Dalam strategi ekspositori, langkah persiapan merupakan langkah yang sangat penting. Keberhasilan pelaksanaan pembelajaran dengan menggunakan strategi ekspositori sangat tergantung pada langkah persiapan.

Beberapa hal yang harus dilakukan dalam langkah persiapan di antaranya adalah

b. Memberikan sugesti yang positif dan menghindari sugesti yang negatif.

c. Memulai dengan mengemukakan tujuan yang harus dicapai.

d. Penyajian (Presentation)

Langkah penyajian adalah langkah penyampaian materi pelajaran sesuai dengan persiapan yang telah dilakukan. Yang harus dilakukan pendamping penyajian ini adalah bagaimana agar materi dapat dengan mudah ditangkap dan dipahami oleh lansia. Karena itu, ada beberapa hal yang dilakukan pendamping dalam pelaksanaan langkah ini, yaitu: penggunaan bahasa, intonasi suara, menjaga kontak mata dengan lansia, dan menggunakan joke-joke yang menyegarkan.

e. Korelasi (Correlation)

Langkah korelasi adalah langkah menghubungkan materi pendampingan dengan pengalaman lansia atau dengan hal-hal lain yang memungkinkan lansia dapat menangkap keterkaitannya dalam struktur pengetahuan yang telah dimilikinya.

f. Menyimpulkan (Generalization)

Menyimpulkan adalah tahapan untuk memahami inti (core) dari materi pendampingan yang telah disajikan.

g. Mengaplikasikan (Application)

Langkah aplikasi adalah langkah unjuk kemampuan lansia setelah mereka menyimak penjelasan pendamping. Melalui langkah ini pendamping akan dapat mengumpulkan informasi tentang penguasaan dan pemahaman materi pendampingan oleh lansia.

\section{Kegiatan Pendampingan Spiritualitas (Sholat dan Wudhu) Bagi Lansia}

a. Mendiskusikan Permasalahan Agama Masyarakat Desa Kare

Agama merupakan pondasi hidup yang harus dimiliki setiap orang. Agama sebagai penerang di setiap lini kehidupan. Agama yang mengantarkan manusia menuju jalan kebenaran. Agama memang berfungsi sebagai rahmatan lil 'alamin. Tidak heran, ketika agama lepas dari jiwa seseorang, dia akan merasakan kehampaan dalam hidup, kegersangan dalam jiwa dan merasa terombang - ambing dalam mengarungi perjalanan hidup.

Masyarakat Desa Kare mayoritas bekerja sebagai petani yang menjadi kesibukan sehari hari. Di saat musim panen, seperti sekarang Desa Kare sedang musim panen cengkeh, disibukkan dengan urusan pertanian. Banyak dari kalangan orangtua yang tidak melaksanakan shalat di mushalla dikarenakan masih disibukkan dengan panen cengkeh. Aktifitas masyarakat desa Kare dari pagi sampai malam rata - rata adalah beraktivitas di bidang pertanian. Hal ini menjadi perhatian bagi tim pengabdian, melihat banyak kalangan masyarakat tua yang belum bisa melakukan shlat dengan baik dan benar.

Saat tim berdiskusi tentang permasalahan tersebut dengan beberapa tokoh masyarakat, seperti KH. Zahro 'Arifin, bapak Suyut, bapak Parno, bapak Tompo (mudin), dan mas Adi (pengasuh mushalla Darus Salam) serta tidak lupa pula TIM berdiskusi dengan bapak Sukirman, maka tim pendampingan menetapkan perrsoalan ini sebagai permasalahan utama yang penting untuk diangkat. Hal ini didukung oleh berbagai pihak.

b. Mengenal Potensi untuk Pencapaian Harapan

Masyarakat desa Kare, khususnya Dusun Kare merupakan masyarakat yang sangat guyup rukun. Selalu ada komunikasi yang terjalin dari masyarakat. Masyarakat Desa Kare selalu membangun kebersamaan dalam segala hal. Hidup bermasyarakat memang sudah menjadi pondasi masyarakat yang sangat teguh.

Tim pengabdian menemukenali potensi serta kekuatan yang ada di Dusun Kare demi 
pencapaian program yang efektif dan maksimal. Setelah tim mengobservasi secara langsung, tim menemukan beberapa potensi dan kekuatan yang ada di dusun Kare. Hal ini dapat dijabarkan sebagaimana berikut:

1) Antusias masyarakat Dusun Kare sangat tinggi untuk belajar tentang agama.

2) Masyarakat Dusun Kare memiliki semangat belajar agama yang tinggi.

3) Banyak pihak yang mendukung pelaksanaan program.

4) Adanya Sumber Daya Manusia (SDM) yang mampu menjadi kader penerus penyiar agama Islam.

c. Kajian Rutin

Tabel 1. Tahap pembelajaran

\begin{tabular}{|c|c|c|}
\hline No. & Tanggal & Materi \\
\hline 1 & 26 Juli 2016 & Perkenalan Islam dan Iman \\
\hline 2 & 27 Juli 2016 & Thaharah \\
\hline 3 & 28 Juli 2016 & Tahlil \\
\hline 4 & 29 Juli 2016 & Wudhu dan Bacaan \\
\hline 5 & 30 Juli 2016 & $\begin{array}{l}\text { Rukun Wudhu dan Sunnah } \\
\text { Wudhu }\end{array}$ \\
\hline 6 & 31 Juli 2016 & Praktek Wudhu \\
\hline 7 & $\begin{array}{l}01 \text { Agustus } \\
2016\end{array}$ & $\begin{array}{lr}\text { Hal } \quad-\quad \text { Hal } & \text { yang } \\
\text { Membatalkan } & \text { Wudhu } \\
\text { (Hadats dan Najis) } & \end{array}$ \\
\hline 8 & $\begin{array}{l}02 \text { Agustus } \\
2016\end{array}$ & $\begin{array}{l}\text { Darah yang Keluar dari } \\
\text { Wanita (Haid, Wiladah dan } \\
\text { Nifas) }\end{array}$ \\
\hline 9 & $\begin{array}{l}03 \text { Agustus } \\
2016\end{array}$ & Perkenalan Shalat \\
\hline 10 & $\begin{array}{l}04 \text { Agustus } \\
2016\end{array}$ & Tahlil dan Shawalat \\
\hline 11 & $\begin{array}{l}05 \text { Agustus } \\
2016\end{array}$ & $\begin{array}{l}\text { Baca'an - Baca'an dalam } \\
\text { Shalat }\end{array}$ \\
\hline 12 & $\begin{array}{l}06 \text { Agustus } \\
2016\end{array}$ & Hafalan Baca'an Shalat \\
\hline 13 & $\begin{array}{l}07 \text { Agustus } \\
2016\end{array}$ & Praktek Shalat \\
\hline 14 & $\begin{array}{l}08 \text { Agustus } \\
2016\end{array}$ & Pengulangan Praktek Shalat \\
\hline 15 & $\begin{array}{l}09 \text { Agustus } \\
2016\end{array}$ & $\begin{array}{l}\text { Pengulangan } \\
\text { Pengarahan }\end{array}$ \\
\hline 16 & $\begin{array}{l}10 \text { Agustus } \\
2016\end{array}$ & $\begin{array}{l}\text { Pengulangan } \\
\text { Pengarahan }\end{array}$ \\
\hline
\end{tabular}

Kajian Rutin dimulai dari tanggal 26 Juli sampai 10 Agustus 2016. Program ini bertujuan untuk pondasi dasar bagi masyarakat khususnya bagi lansia yang menjadi fokus dari pokok permasalahan, yakni menjadikan masyarakat khususnya lansia untuk bisa melaksanakan shalat dengan baik dan benar. Kajian ini dipandu oleh saudara Imam Mustakim, Khoirun Niswah dan Khoiro Ummah.

Adapun tahap pembelajaran dari hari per hari sebagaimana Tabel 1

Setelah diadakan kajian agama secara rutin, alhamdulillah terjadi perubahan yang sangat baik dari jamaah yang mengikuti kajian. Awalnya, lansia atau masyarakat tidak memahami tata cara wudhu dan bacaan shalat dengan baik dan benar, sekarang sudah bisa memahami tentang wudhu dan shalat dengan baik.

d. Pengkaderan atau Regenerasi

Pengakaderan ini dimaksudkan agar adanya penerus yang melanjutkan kegiatan pendampingan keagamaan. Ada dua (2) SDM yang telah mampu untuk meneruskan kajian Islam, yakni Bapak Suyut dan Bapak Tompo (mudin). Kajian ini berupa pencerahan agama yang akan dilakukan tiga kali dalam seminggu. Tim pendamping juga memberi kenang - kenangan berupa dua kitab, yakni kitab Riyadhus Sholihin dan Safinatun Najah sebagai bantuan bahan kajian selanjutnya.

\section{PENUTUP}

Masyarakat Desa Kare khusunya lansia memiliki memiliki kelemahan dalam bidang agama untuk mewujudkan masyarakat agamis yang berbahagia sesuai dengan tugas perkembangan usia lanjut lebih banyak berkaitan dengan kehidupan pribadi seseorang daripada kehidupan orang lain.

Pelatihan pendalaman spiritualitas difokuskan dalam ibadah sholat dan wudhu sebagai syarat sah sholat dengan metode pembelajaran eksporitori dengan langkah dalam penerapan Metode ekspositori, yaitu: Persiapan (Preparation), Penyajian (Presentation), Korelasi (Correlation), yang dilaksanakan dalam waktu tiga minggu, dengan tambahan proses pengkaderan masyarakat yang dirasa mamu meneruskan program tersebut.

Pelatihan atau program selanjutnya diharapkan dapat menjangkau masyarakat Desa Kare lebih luas dengan pemilihan metode yang lebih efektif dan pemberian materi yang lebih banyak, diharapkan dengan hal tersebut akan terbentuk masyarakat lebih agamis dan berbahagia. 
Spirituality Building Bagi Lansia: Pengalaman Pendampingan pada Lansia di Desa Kare Kecamatan Kare Kabupaten

Madiun

\section{Daftar Pustaka}

Amawidyati \& Utami. 2006. "Religiusitas dan Psychological Well Being Pada Korban Gempa", Dalam Jurnal Psikologi Universitas Ahmad Dahlan humanitas Vol. 3 No. 2,

B.E., Hurlock, Psikologi Perkembangan: Suatu Pendekatan Sepanjang Rentang Kehidupan, (Jakarta: Erlangga, 1999)

David D. Burns, M. D. 1988. Mengapa Kesepian, Program Baru yang Telah diuji Secara Klinis untuk Mengatasi Kesepian. Jakarta: ed. Ardy Handoko.

D. E. Papalia, "A Child World : Infancy Through Adolescence", (6th ed), (New York: Mc Graw-Hill, 1993)

Departemen Agama RI. 2009. Al-Qur'an dan Terjemahanya. Jakarta:Amzah.

Hasan, Abdul Wahid SQ Nabi. Aplikasi Strategi Dan Model Kecerdasan Spiritual (SQ) Rasululullah di Masa Kini. (Yogyakarta:IRCiSod, 1996)

J.W, Santrock Life-Span Development: Perkembangan Masa Hidup (edisi kelima). Penerj. Achmad Chusairi, Juda Damanik; Ed. Herman Sinaga, Yati Sumiharti, (Jakarta: Erlangga, 2002) 